\title{
Individual Difference in Goal Motives and Goal Content: The Role of Action and State Orientation
}

\author{
Rui Shi, ${ }^{1, *}$ Shilei Zhang, ${ }^{2,3, *}$ Danmin Miao, ${ }^{4}$ Qianwen Zhang, ${ }^{3}$ Zhenhong Wang, ${ }^{2}$ and \\ Yan Zhang ${ }^{4}$ \\ ${ }^{1}$ College of Humanities and Social Development, Northwest A\&F University, Yang Ling, P.R. China \\ 2 School of Psychology, Shaanxi Normal University, Xi'an, P.R. China \\ 3 Psychological Counseling Centre, Chang'an University, Xi'an, P.R. China \\ ${ }^{4}$ Department of Psychology, Fourth Military Medical University, Xi'an, P.R. China
}

\begin{abstract}
The purpose of this study was to investigate whether hesitant or preoccupied people (state-oriented) have different goal content and motives compared to initiative or disengaged people (actionoriented). People rated the degree of autonomous versus controlled feelings for extrinsic or intrinsic types of goals. Results showed that action-oriented people had a higher autonomous motive than stateoriented people for intrinsic goals, but not for extrinsic goals. Moreover, action-oriented individuals were related to a more internalised goal content (intrinsic goal) than state-oriented individuals. Implications for goal internalisation are discussed.
\end{abstract}

Keywords: action-state orientation, autonomous motivation, extrinsic, intrinsic, goal

Broadly speaking, self-regulation involves the psychological processes that allow individuals to adjust their thoughts, actions, and feelings to align with their standards, goals, and values (Carver \& Scheier, 2001). One's capacity to initiate action toward goal attainment is a function of a person's self-regulation ability and plays a central role in goal striving (Kuhl, 1985). Kuhl and colleagues put forward the action control theory and the personality system interaction (PSI) theory to elucidate individual differences in self-regulation ability and yielded fruitful results across a wide range of domains, such as interpersonal relationships (Backes et al., 2016), cognitive control (Fischer, Plessow, Dreisbach, \& Goschke, 2015; Kaschel, Kazén, \& Kuhl, 2017; Wolff et al., 2016), decision making (van Putten, Zeelenberg, \& van Dijk, 2013), and job performance (Diefendorff, Hall, Lord, \& Strean, 2000; Landman, Nieuwenhuys, \& Oudejans, 2016).

Action control theory and PSI theory posit that these individual differences in self-regulation ability are comprised of action orientation and state orientation (Kuhl, 1984, 1985, 1987, 2000, 2001; Kuhl \& Goschke, 1994). Action orientation is a personality that facilitates the goal-striving process. These individuals take the initiative in goal striving, even in contrary conditions such as monotony or stress (Jostmann \& Koole, 2006; Koole \& Jostmann, 2004). In contrast, state orientation is a personality that has difficulty in taking action toward goal fulfillment. Moreover, state-oriented people are unable to volitionally control intrusive thoughts triggered by negative affect after stress, resulting in preoccupation. Actionoriented people, however, are able to disengage from intrusive thoughts elicited by negative events (Kuhl, 2000).

According to Kuhl's action control theory, action- and state-oriented people may also have different goal internalisation processes (Kuhl, 2001; Kuhl \& Kazén, 1994; Kuhl, Quirin, \& Koole, 2015). Here, internalisation means 'taking in' the value or regulation of goals, attitudes, standards, and beliefs of significant others (Ryan \& Deci, 2000). There are various degrees of internalisation. For instance, informed introjections refer to individuals' internalisation of what others expect them to do, yet they perceive that these expectations are not part of themselves (Kuhl \& Kazén, 1994); and misinformed introjections refer to individuals' internalisation of what others expect them to do, yet they perceive these expectations are part of themselves explicitly but not implicitly. Integration refers to the internalisation of social values and expectations congruent with a greater portion of one's values (Deci \& Ryan,

Address for correspondence: Shilei Zhang, School of Psychology, Shaanxi Normal University, Xi'an, No. 620, West Chang'an Avenue, Chang'an District, Xi'an 710119, P.R. China. Email: 75597236@qq.com

* Shared first authorship 
1991; Ryan, 1995; Sheldon \& Kasser, 2008; Sheldon, Ryan, Deci, \& Kasser, 2004); these values and goals of social expectations are congruent with the heart of self-identity, whereas the informed and misinformed introjections are not. Therefore, both informed and misinformed introjections are less concerned with internalisation goals and are less self-determined. As they lack autonomy, they may be often not be supported by one's actual feelings and may even conflict with implicit needs and preferences (Kuhl \& Kazén, 1994; Thomsen, Tønnesvang, Schnieber, \& Olesen, 2011).

Empirical evidence also indicates that action and state orientation have different goal internalisation processes. Action-oriented people are inclined toward selfmotivation and choose self-congruent goals - especially when confronted with demands and threats (Koole \& Jostmann, 2004). More importantly, research has also found that goal commitment is positively associated with the congruence between goals and motives in actionoriented people; however, this pattern was not found in state-oriented people (Brunstein, 2001). State-oriented people can overcome their lack of initiative only through an externally controlled mode (Baumann \& Kuhl, 2005), which is a less significant internalisation process. In contrast, action-oriented people prefer an autonomy-driven type of self-regulation that does not depend on a controlled model of regulation (Baumann \& Kuhl, 2005). Taken together, much of the research is focused on actionstate orientation's difference in goal internalisation by assessing the motive congruence of implicit and explicit motives, which is an index of misinformed introjections (Baumann \& Kuhl, 2003; Brunstein, 2001; Guevara, 1994; Koole \& Jostmann, 2004; Kuhl, 1994). As mentioned before, informed introjections are also an important process of goal internalisation. However, little attention has been paid to informed introjections' differences in action-state orientation. Although action control theory posits that action-state oriented people have different misinformed and informed introjections, there remains a paucity of empirical evidence on informed introjections.

In the current study, we adopt both goal motive and goal content as an index of goal internalisation for the following reasons. According to the self-concordance (SC) model (Sheldon, 2014; Sheldon \& Elliot, 1999), which is grounded in self-determination theory (SDT; Deci \& Ryan, 1985; Ryan \& Deci, 2000), goal motives are the reasons why our pursuit of goals can be sorted by personal interest, enjoyment, and perceived importance (categorised as autonomous motive), and can also be driven by internal or external pressures that are related to social or others' praise and approval and expectations (categorised as controlled motive). The SC model demonstrates that autonomous motives foster sustained efforts in individuals' goal striving, especially in difficult or failure situations (Sheldon, 2008). Recent research has supported that autonomous goal motives are associated with greater per- sistence, positive affect, and task engagement (Ntoumanis et al., 2014). Besides goal motive, goal content, which is the kinds of goals we pursue, is also associated with internalisation. According to SDT, intrinsic goal contents are more concordant with people's basic needs, whereas extrinsic goal contents may be less concordant with people's basic needs (Ryan \& Deci, 2000). Thus, intrinsic goals are more internalised than extrinsic goals (Sheldon \& Kasser 1998; Sheldon et al., 2004). This is in line with goal internalisation processes in action control theory, which assesses that the volitional ability to facilitate or impede the enactment of intentions is assumed to be closely associated with goal internalisation (Kuhl \& Beckmann, 1994; Müller \& Rothermund, 2017).

The current study aims to explore whether action-state oriented people have different informed introjections that can be directly assessed by intrinsic (extrinsic) goal content and goal motive questionnaires. This might add to our understanding of individual differences in the goal internalisation process and provide empirical evidence for the overlap between action control and goal internalisation theory; it might also provide new insights of the 'autonomy' concept in both action control and selfdetermination theories. Moreover, as goal content and goal motive are also two facets of goal internalisation, investigating action orientation's difference in the goals pursued and why they are pursued would systematically test the relationship between self-determination theory and action control theory. It is hoped that this might advance a deeper understanding of the function of goal motive and goal content in the goal-striving process. Bringing action control theory and SDT together, we infer that stateoriented people may have fewer internalised goal motives and content than action-oriented individuals. Moreover, we hypothesised that state-oriented and action-oriented individuals have a different autonomy of goal motives according to goal content.

\section{STUDY 1 \\ Method \\ Participants and Procedure}

Four hundred and forty-two (230 males, $M_{\text {age }}=21.8$ years) college students volunteered to participate in this study. Participants were from a large public university in Xi'an city, China. They were recruited by advertisements on campus and received course credits for extracurricular activities for their participation. They first completed the Action Control Scale (ACS-90; Kuhl, 1994) when they arrived at the laboratory. Considering all variables are measured by self-reported data, the current study adopted a time gap design between two questionnaires. This procedure aims to lower the impact of common method bias on results. A week later, the participants returned to the laboratory to complete the goal motive questionnaire. Prior to data collection, the research ethics committee of the university gave ethical approval. After 
completion of the scale, the participants were thanked and debriefed. As the participants could receive course credits for extracurricular activities for participation, only six participants were excluded for missing data (they failed to take part in the study at the second time-point).

\section{Questionnaires}

Action orientation. Individual differences in action and state orientation were assessed by the ACS-90 in Chinese (Song, Wanberg, Niu, \& Xie, 2006). The ACS-90 has showed good validity and reliability in previous studies (Diefendorff et al., 2000; Kuhl \& Beckmann, 1994). The ACS-90 has three subscales (12 items each that use a forced-choice measurement. The three subscales are: the preoccupation (AOF) subscale, which assesses disengagement ability from thoughts elicited by a past selfthreatening experience; the AOD subscale, which assesses difficulties in initiating self-regulation action towards a goal; and the volatility (AOP) subscale, which assesses the ability to persevere (cf. Kuhl, 1994). As the AOP subscale aims to measure the ability to keep focused on self-initiated and pleasant activities, this personality may be linked to autonomous goal internalisation, and therefore this dimension was not dealt with in the current study. According to the aims of study 1 , we adopted the AOD and AOF subscales (Diefendorff et al., 2000). The AOD subscale assesses individuals' hesitation or initiation to start activities in a demanding situation (Kuhl 1994). An example item is: 'When I know I must finish something soon: (a) I have to push myself to get started (state-oriented response alternative), or (b) I find it easy to get it done and over with (action-oriented response alternative).' The AOF subscale assesses an individual's disengagement ability for undesirable experiences and failure. An example item is: 'When something really gets me down: (a) I have trouble doing anything at all (state-oriented response alternative), or (b) I find it easy to distract myself by doing other things (action-oriented response alternative).' Participants with a score of more than $7(\geq 7)$ would be placed in the actionoriented group and the remainder with a score less than $6(\leq 6)$ would be in placed in the state-oriented group (total score 12; Cronbach's alpha of AOD and $\mathrm{AOF}=.73$, .75 respectively; Ruigendijk \& Koole, 2014). For the AOF, there were 212 and 230 participants in subgroups for action and state orientation, respectively. For the AOD, there were 216 and 226 participants in subgroups for action and state orientation, respectively.

\section{Goal Content and Goal Motives}

To assess goal content and goal motives, we adopted a previously used measurement in goal-striving research (Sheldon et al., 2004; Smith, Ntoumanis, \& Duda, 2007).

Upon arrival at the laboratory, participants were presented with six personal goals that are often pursued in life. These comprised three intrinsic goals: emotional intimacy ('Having many close and caring relationships with oth- ers'), personal growth ('Being fulfilled and having a very meaningful life'), and community contribution ('Helping to make the world a better place'); and three extrinsic goals: fame/popularity ('Being known and/or admired by many people'), attractive image ('Looking good and appearing attractive to others'), and financial success ('Getting a job that pays very well and having a lot of nice possessions') (the exact wording is in Sheldon et al., 2004).

Afterwards, participants were asked to rate the importance of the reasons why they pursued these six goals according to two types of four reasons (Ryan \& Connell, 1989; Sheldon \& Elliot, 1998, 1999; Sheldon \& Kasser, 1998), which included two autonomous reasons: 'Because you identify with the goal from the bottom of your heart' (identified motivation) and 'Because the goal could provide you enjoyment or excitement' (intrinsic motivation); and two controlled reasons: 'Because you feel you are expected to do so (because somebody else wants you to or because the situation seems to compel it)' (external motivation) and 'Because you would feel ashamed, guilty, or anxious if you did not have this goal' (introjected motivation). Participants assessed the degree of importance for each reason they pursued the six goals using a 5-point scale $(1=$ not at all, $5=$ very much so).We adopted the relative autonomous motive strength as the index of dependent variable, which has been used in previous research (Sheldon et al., 2004). By summing the two autonomous motivation ratings and then subtracting the two controlled motivation ratings (Sheldon \& Elliot, 1998, 1999), the relative strength of the autonomous goal motive for extrinsic and intrinsic goal content were assessed.

\section{Results \\ Preliminary Analyses}

In preliminary analyses, we investigated whether extrinsic versus intrinsic goal contents would differ in the average degree of autonomy (Au-ex vs. Au-in). Findings showed that Au-ex were lower than $\mathrm{Au}$-in, $\mathrm{Ms}=2.28$ vs. 3.32, $t(435)=-11.29, p<0.001$. The Cronbach's alpha for autonomous motives was 0.85 , and for controlled motives it was 0.83 .

\section{Primary Analyses for AOD}

The within-subject factor of goal content (intrinsic and extrinsic) and the between-subjects factor AOD were taken as repeated-measurement ANOVAs with autonomous ratings as dependent variables (see Figure 1). This analysis showed a significant main effect of action-state orientation, $F(1,434)=7.55, p<.01, \eta^{2}{ }_{p}=0.02$, and goal content, $F(1,434)=121.104, p<.001, \eta_{p}^{2}=0.22$. More importantly, this analysis revealed the expected two-way interaction between AOD and goal content, $F(1,434)=12.92$, $p<.01, \eta_{p}^{2}=0.02$. To investigate this interaction further, we compared the action and state orientation's goal motive in extrinsic and intrinsic goal content separately (Bonferroni correction). For extrinsic goals there was no 


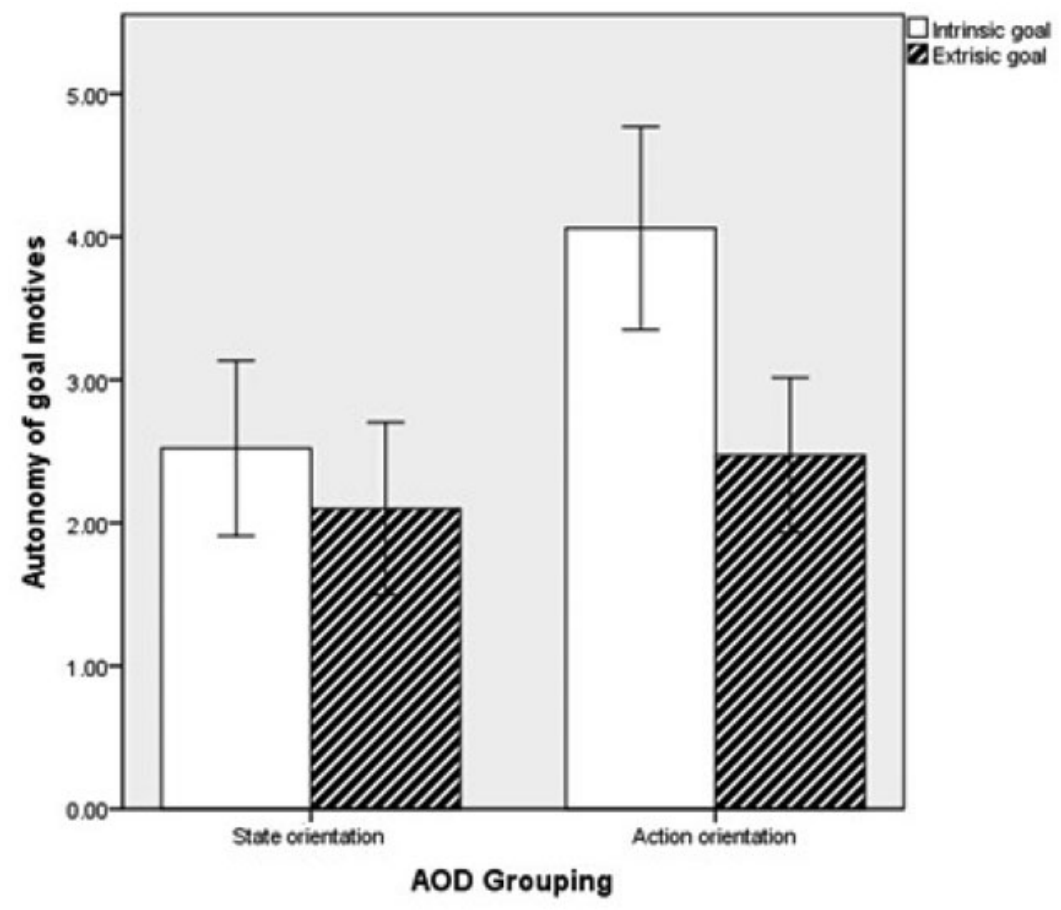

Error Bars: $95 \% \mathrm{Cl}$

\section{Figure 1}

Autonomy of goal motives for intrinsic/extrinsic goal in demand related action-state orientation. Note: AOD Grouping group sorted by demand related action orientation scale.

difference between action and state orientation's goal motives, $t(434)=-0.79, p>.2$. Whereas for intrinsic goals, action-oriented individuals had higher autonomous goal motives than state oriented individuals, $t(434)=-3.40$, $p<.001$. Also for action-oriented individuals, their intrinsic goal content had higher autonomous motive than their extrinsic goal content's motive $\left(M_{\text {diff }}=3.10, p<\right.$ $.001)$. But for state-oriented people, their intrinsic goal content's motive did not differ from their extrinsic goal content's motive $\left(M_{\text {diff }}=.85, p>.05\right)$. Using any type of dichotomisation or a median split approach is questionable because it is known to create spurious interactions that are generally not discovered when the variable is kept on a continuous scaling (Bissonnette, Ickes, Bernstein, \& Knowles, 1990). Thus, we also ran a regression analysis, and results showed that AOD could positively predict autonomy of intrinsic goal content's motive, $t(435)=5.10$, $\beta=0.24, p<.001$, but not autonomy of extrinsic goal content's motive, $t(435)=1.22, \beta=0.05, p=.21$.

\section{Primary Analyses for AOF}

As with the AOD, we adopted repeated-measurement ANOVAs with autonomous ratings as dependent variables (see Figure 2). This analysis revealed a significant main effect of action-state orientation, $F(1,434)=6.99, p<.05$, $\eta_{p}^{2}=0.02$, and goal content, $F(1,434=133.43, p<.001$, $\eta_{p}^{2}=0.24$. More importantly, this analysis revealed the expected two-way interaction between action orientation and goal content, $F(1,434)=8.79, p<.001, \eta_{p}^{2}=0.02$. To investigate this interaction further, we compared the action and state orientation's goal motive in extrinsic and intrinsic goal content separately (Bonferroni correction). For extrinsic goals there was no difference between action and state orientation's goal motives, $t(436)=-1.14$, $p=.26$, whereas for intrinsic goals, action-oriented individuals had higher autonomous goal motives than stateoriented individuals, $t(436)=-3.53, p<.001$. Also, for action-oriented people, their intrinsic goal content had higher autonomous motive than their extrinsic goal content's motive $\left(M_{\text {diff }}=2.09, p<.001\right)$. For state-oriented people, their intrinsic goal content's motive was different from their extrinsic goal content's motive $\left(M_{\text {diff }}=0.8, p<\right.$ $.02)$. We also ran a regression analysis. and results showed that AOF could positively predict autonomy of intrinsic goal content's motive, $t(435)=3.60, \beta=0.17, p<.001$, but not autonomy of extrinsic goal content's motive, $t(435)=$ $1.30, \beta=0.06, p=.19$.

\section{Correlational Analysis}

Here, we aimed to complement our findings by adding a correlational analysis in order to replicate the findings. We tested our hypothesis by viewing action and state orientation as continuous variables (Table 1). Thus, 149 new participants completed the goal content, goal motive, and action-state orientation (AOF subscale) measurement. As expected, the action-state score positively correlated with 


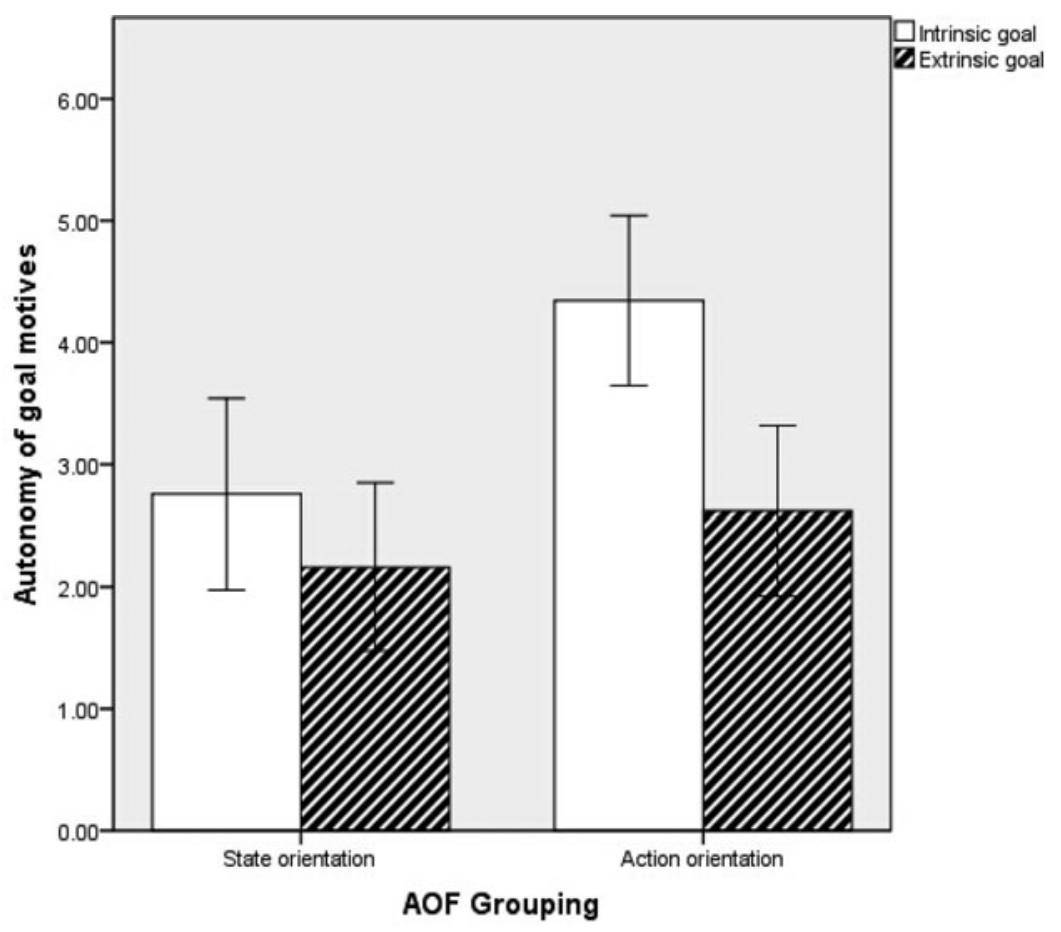

Error Bars: $95 \% \mathrm{Cl}$

\section{Figure 2}

Autonomy of goal motives for intrinsic/extrinsic goal in threat (failure) related action-state orientation. Note: AOF Grouping group sorted by threat (failure) related action orientation scale.

Table 1

Correlations, Means, and Standard Deviations of Variables (Study 1)

\begin{tabular}{lllcc}
\hline Variable & 1 & 2 & 3 & 4 \\
\hline 1. AOD & - & & & \\
2. AOF & $0.33^{* *}$ & - & & \\
3. Au-in & $0.24^{* *}$ & 0.17 & - & \\
4. Au-ex & 0.05 & 0.06 & $0.22^{* *}$ & - \\
$M$ & 6.73 & 6.10 & 10.01 & 7.28 \\
SD & 2.64 & 2.9 & 6.14 & 5.59
\end{tabular}

Note: $n=436 ; \mathrm{AOD}=$ demand related action orientation, $\mathrm{AOF}=$ failure related action orientation, $\mathrm{Au}$-in = autonomy of intrinsic goal motive, $\mathrm{Au}-\mathrm{ex}=$ autonomy of extrinsic goal motive.

$*^{* *} p<.01$

autonomous goal motives for intrinsic goal, $r=.22, p<$ .006 , but not with extrinsic goal, $r=.12, p>.13$.

\section{STUDY 2A}

Study 1 supported the main idea that state orientation (hesitation) is associated with controlled goal motives while the action orientation (initiative) is associated more with autonomous goal motives. In study 2, we aimed to further test this hypothesis, whether goal content would distinguish between action and state orientation. According to SDT, extrinsic goals are inherently less congruent with people's basic needs, while intrinsic goals are typically inherently rewarding (Ryan \& Deci, 2000). Instead, extrinsic goals involve external rewards and the others' evaluations. Compared to intrinsic goals, extrinsic goals are less internalised (Sheldon \& Kasser, 1998; Sheldon et al., 2004). The relative extrinsic versus intrinsic value orientation (REIVO) of personal goals has been found to be associated with negative outcomes of wellbeing (Kasser \& Ahuvia, 2002; Ryan et al., 1999). Thus, study 2 aimed to test whether the REIVO of personal goals was associated with action-state orientation.

\section{Method \\ Participants and Procedure}

Two hundred and sixteen college students were recruited, comprised of 136 women and 80 men $\left(M_{\text {age }}=26.28\right.$, $S D=4.13$ ), from a large public university in Xi'an city, China. They were recruited by advertisements on campus and received course credits for extracurricular activities for their participation. They arrived at the laboratory to complete the ACS-90 (AOD subscale). Three weeks later, participants returned and first wrote down five personal goals (Emmons, 1989; Little, 1993). The five goals were their important personal goals that they had been striving toward in the past year. Examples were provided (i.e., 'lose 5kg', 'read a book'). As the participants could receive course credits for extracurricular activities for participation, only 10 participants were excluded for missing data (they failed to take part in the study at the second time-point). 


\begin{tabular}{lcc}
\hline $\begin{array}{l}\text { Table } 2 \\
\text { Correlations, Means and Standard Deviations of Variables (Study 2a) }\end{array}$ & 2 \\
\hline Variable & & \\
\hline 1. AOD & - & - \\
2. REIVO & $-0.20^{* *}$ & -54.01 \\
$M$ & 6.71 & 15.44 \\
SD & 2.66 & \\
\hline Note: $n=216 ;$ AOD = demand related action orientation, REIVO = relative extrinsic \\
to intrinsic score. \\
$* * p<.01$
\end{tabular}

\section{Questionnaires}

Action orientation was assessed using the ACS-90 (AODsubscale), which was same scale used in study 1 (Cronbach's alpha $=.72$ ).

The REIVO was adopted from Sheldon and Kasser (1998, 2000). Participants assessed to what extent each of their five goals would help the fulfillment of three intrinsic (e.g., 'It is important for me to build solid and intimate friendships') and three extrinsic (e.g., 'It is important for me to be financially successful in life') possible futures (5-point Likert scale). The relative autonomy score could be calculated by deducting the intrinsic goals from the extrinsic goals (Sheldon \& Kasser, 1998; $\alpha$ $=.75)$.

\section{Results}

Pearson correlations were calculated to examine whether action-state orientation would be associated with goal content. The results showed that the AOD score was significantly negatively correlated with the REIVO ( $r=$ $-.20, p<.004)$. Regression analysis showed that the AOD score negatively predicted the REIVO, $t(216)=-2.94$, $\beta=-0.20$ (Table 2).

\section{Discussion}

The results of study 1 indicate that action-oriented people have higher autonomous motivation than state-oriented people. Action control can be associated with people's striving for enjoyment or personal importance. Actionoriented individuals are more likely to have autonomous goal motives, whereas state-oriented individuals are more likely to have controlled goal motives.

The results of this study also showed that actionoriented people had higher autonomous goal motives for intrinsic goal content than for extrinsic goal content, whereas there was no significant difference found in stateoriented people. According to the goal content and motive model, intrinsic goal content is usually regulated by autonomous motives, while extrinsic goal content is often regulated by controlled motives. According to PSI theory, this is probably because autonomous internalisation requires the ability to self-generate positive affect, which can foster the integration process. Moreover, this requirement is even stronger for intrinsic goal content than for extrinsic goal content. Kuhl assumed that state orienta- tion denotes a low ability to produce positive affect (Koole \& Jostmann, 2004; Kuhl \& Beckmann, 1994). Thus, this may cause state-oriented people to be unable to form autonomous motivation for intrinsic goal content and lack the ability to self-motivate in the presence of challenging demands and difficulties (which can be directly measured by the AOD subscale). The present findings appear to be consistent with other research showing that state-oriented people are more prone to making a commitment to unrealistic and need-incongruent goals than are action-oriented people (Brunstein, 2001). One last finding arose in study 1. Action orientation was shown to be negatively associated with the relative strength of extrinsic goal content. State-oriented individuals tend to value more external and introjected goals over intrinsic goals than action-oriented individuals. According to SDT, intrinsic goals are more internalised than extrinsic goals (Sheldon \& Kasser, 1998; Sheldon et al., 2004). Thus, the results from two different assessments of internalisation indicate that the degree of internalisation may differentiate action-oriented and state-oriented individuals.

\section{STUDY 2B \\ Method \\ Participants and Procedure}

Two hundred and seventy-six college students were recruited, comprising 60 women and 216 men $\left(M_{\text {age }}=22.13\right.$, $S D=3.8$ ). They were from a large public university in Xi' an city, China. They were recruited by advertisements on campus and received course credits for extracurricular activities for their participation. They arrived at the laboratory to complete the ACS-90 (AOF subscale, $\alpha=.76$ ). Three weeks later, participants completed the REIVO, as with study 2 a (five people missed the second time-point, $\alpha=.72$ ). As the participants could receive course credits for extracurricular activities for participation, only eight participants were excluded for missing data (they failed to take part in study at the second time-point).

\section{Results}

We tested the relationship between action-state orientation and goal content with Pearson correlations. The results confirmed the prediction that the AOF score would be significantly negatively correlated with the REIVO $(r=-.21, p<.001)$. Regression analysis showed that AOF score negatively predicted the REIVO, $t(268)=-3.63$, $\beta=-0.21$ ) (Table 3).

\section{Discussion}

As mentioned in the literature review of action control theory, some individuals have trouble initiating behaviours toward goal pursuit. Kuhl and Kazén (1994) additionally hypothesised that some individuals who ruminate about past failures have internalisation issues. The current study found that action-oriented (disengaged) people had higher levels of autonomous motivation than 
Table 3

Correlations, Means and Standard Deviations of Variables (Study 2b)

\begin{tabular}{lcc}
\hline Variable & 1 & 2 \\
\hline 1. AOF & - & \\
2. REIVO & $-0.21^{* *}$ & - \\
$M$ & 6.59 & -53.04 \\
$S D$ & 2.32 & 16.39
\end{tabular}

Note: $n=268 ; \mathrm{AOF}=$ failure related action orientation; REIVO = relative extrinsic to intrinsic score

** $p<.01$

state-oriented (preoccupied) individuals. Moreover, the present study showed no significant differences between action-oriented and state-oriented people pertaining to autonomous goal motives for extrinsic goals. This pattern of findings is similar to those of study 1 . The results of this study will now be compared to the findings of previous work.

Thomsen et al. (2011) found that rumination was positively associated with extrinsic goals, while reflection was positively associated with intrinsic goals. Their study used different types of measures to assess internalisation and its association with rumination and reflection. It is of note that rumination was the most typical indicator and behavioural consequence of state orientation in this study. Such an effect is postulated by PSI theory, in which a possible explanation for this result is that state-oriented people have a lower ability to reduce negative affect, which might impede access to one's own core wishes, goals, and preferences (Kuhl, 1994; Kuhl \& Kazén, 1994). Thus, stateoriented people would be less likely to fully internalise and integrate goals, and finally pursue controlled (i.e., not wellinternalised) goals (Kuhl \& Beckmann, 1994). In contrast, action-oriented people are able to down-regulate negative affect in threatening conditions, thus promoting the formation of realistic and self-congruent goals.

The results of study $2 \mathrm{a}$ and study $2 \mathrm{~b}$ also indicated that threat-related AOF is negatively associated with the relative strength of extrinsic goal content. This finding is consistent with the results of study 1 . It confirms the association between internalised goal and action-state orientation and also extends these findings to the second dimension of the action control scale (AOF).

\section{General Discussion}

Literature on PSI theory has hypothesised that internalisation of goals is critical for distinguishing between action and state orientation. However, very little attention has been paid to the role of goal striving in relation to this dimension of personality. The aim of the present study was to explore this relationship. In two studies we found evidence for the hypothesis that AOD and AOF are related to goal internalisation. Specifically, study 1 found that AOD and AOF were correlated with autonomous goal motive, while study $2 \mathrm{a}$ and study $2 \mathrm{~b}$ found that AOD and AOF were correlated with autonomous goal content. Similar to misinformed introjections, informed introjections are also associated with action-state orientation. The results advance our understanding of the association between individual difference in self-regulation ability and the goal internalisation process by providing empirical evidence for the assumption of PSI theory and self-determination theory.

The present research complements and extends previous investigations by supporting the central hypothesis that the internalisation of goals (including goal content and goal motives) plays a key role in self-regulation (Deci \& Ryan, 2000). Taken with these past findings, the present research further illustrates that inter-individual difference in self-regulation ability is associated with different autonomous goal motives. Individuals with more autonomous motives and goal content are able to overcome difficulties in striving for a goal in demanding or threatening situations. Thus, the current studies are in line with the volitional ability associated with goal internalisation, which might promotion integration with SDT and action control theory in future studies. According to PSI theory, the differences between state- and action-oriented participants should only be observed under stressful conditions. Under stress, state-oriented individuals may not be able to discriminate between self-congruent (intrinsic) and less self-congruent (extrinsic) goals. Baumann and Kuhl (2003) and Kazén et al. (2003) found differences in internalisation between $\mathrm{SO}$ and $\mathrm{AO}$ only under stress. There is only one study, by Kuhl and Kazén (1994), where SO showed more introjection as a main effect. However, the present study found reliable main effects of $\mathrm{SO} / \mathrm{AO}$ (without current stress) across all studies. Because the ability to generate positive affect and reduce negative affect is a fundamental difference between action-oriented and state-oriented people, this difference may be associated with different goal internalisation in demand or threat situations. However, previous studies have found differences in goal internalisation (misinformed introjections) for action/state orientation in stressful or demanding conditions, and also sometimes in normal conditions (Brunstein, 2001; Kuhl, 1994).

While the current study did not measure or induce threat, demand or affect states, it adopted a convenience sample at a highly regarded university during the examination period. It is possible that the general stress level of participants was relatively high across the samples because they completed the questionnaires during the examination month at the end of the semester. Also, the students were recruited from a college that has difficult exams. Thus, it is possible that their general level of negative affect may have been higher than usual, especially for state-oriented people. It is also possible that cultural or socialisation practices could explain the differences between the current findings and previous studies (Kuhl \& Kazén, 1994; Kazén et al., 2003) concerning the role of stress and goal introjection. Previous studies have found that the level of commitment to social norms is systematically higher in collectivistic 
cultures than in individualistic cultures (Heinrichs et al., 2006; Triandis, 1988). Thus, the state-oriented individuals in Western countries may need some reminder of negative affect to be influenced by (implicit) social pressure, leading to introjection or self-infiltration, which is not needed by Chinese participants. This is a question that deserves systematic research in future studies.

\section{Limitations and Future Perspectives}

The present studies have a number of limitations. These limitations pertain to common method bias, alternative explanations for results, and unintended mediators. The present research may be subject to common method bias because it relied on a cross-sectional design. It is thus possible that common method variance has allowed for correlations to be inflated. Future studies using other methodologies, or implementing statistical strategies that reduce common method bias, would help to more fully explore the effects found here.

Second, the relationship between internalisation and action orientation is likely dynamic, in that the elements of action-state orientation and internalisation of goals probably influence one another. Thus, there are alternative interpretations for our results. For instance, while less autonomous goal motives can lead to less action orientation (hesitation or preoccupation in threatening or demanding situations), the opposite might also be true. Because the ability to generate positive affect and reduce negative affect is a fundamental difference between action-oriented and state-oriented people, pursing extrinsic or intrinsic goals may interact with these characteristics. Thus, prospective studies would benefit future research.

\section{Conclusion}

In conclusion, the fact that action-state orientation can be associated with goal internalisation suggests that internalisation plays a key role in distinguishing between action and state orientation. The current study integrated the goal-striving view in the PSI and SDT, which may contribute to the development of effective interventions to help people who hesitate or ruminate in difficult and challenging goal-striving phases. Also, because people with less autonomous goal internalisation may experience less wellbeing, it is important to provide more opportunities and choices to adolescents in order to foster their selfdetermined goal internalisation.

\section{Acknowledgments}

The authors appreciated the anonymous reviewers who made very helpful comments on an earlier version of this article. This research was supported by Grant No. 2016RKX-08 from the Science and Technology Planning Project of the Yang Ling Demonstration Zone, Grant No. 17XJC190009, 17YJC840030 from the MOE (Ministry of Education in China) Project of Humanities and Social Sciences, China Postdoctoral Science Foundation
(2016M592739), Fundamental Research Funds for the Central Universities (310850170325), and the Projects of Social Development (2016-SF-201).

\section{Conflict of Interest}

None.

\section{References}

Backes, S., Brandstätter, V., Kuster, M., Nussbeck, F.W., Bradbury, T.N., Bodenmann, G., \& Sutter-Stickel, D. (2016). Who suffers from stress? Action-state orientation moderates the effect of external stress on relationship satisfaction. Journal of Social and Personal Relationships, 34, 894-914

Baumann, N., \& Kuhl, J. (2003). Self-infiltration: Confusing assigned tasks as self-selected in memory. Personality and Social Psychology Bulletin, 29, 487-497.

Baumann, N., \& Kuhl, J. (2005). How to resist temptation: The effects of external control versus autonomy support on self-regulatory dynamics. Journal of Personality, 73, 443-470.

Bissonnette, V., Ickes, W., Bernstein, I., \& Knowles, E. (1990). Personality moderating variables: A warning about statistical artifact and a comparison of analytic techniques. Journal of Personality, 58, 567-587.

Brunstein, J.C. (2001). Personal goals and action versus state orientation: Who builds a commitment to realistic and needcongruent goals? Zeitschrift fur Differentielle und Diagnostische Psychologie, 22, 1-12.

Carver, C.S., \& Scheier, M.F. (2001). On the self-regulation of behavior. New York, NY: Cambridge University Press.

Deci, E.L., \& Ryan, R.M. (1985). The general causality orientations scale: Self-determination in personality. Journal of Research in Personality, 19, 109-134.

Deci, E.L., \& Ryan, R.M. (1991). A motivational approach to self-integration in personality. In R. Dienstbier (Ed.), $\mathrm{Ne}$ braska symposium on motivation Vol. 38. Perspectives on motivation (pp. 237-288). Lincoln, NE: University of Nebraska Press.

Deci, E.L., \& Ryan, R.M. (2000). The 'what' and 'why' of goal pursuits: Human needs and the self-determination of behavior. Psychological Inquiry, 11, 227-268.

Diefendorff, J.M., Hall, R.J., Lord, R.G., \& Strean, M.L. (2000). Action-state orientation: Construct validity of a revised measure and its relationship to work-related variables. Journal of Applied Psychology, 85, 250-263.

Emmons, R.A. (1989). The personal striving approach to personality. In L.A. Pervin (Ed.), Goal concepts in personality and social psychology (pp. 87-126). Hillsdale, NJ: Lawrence Erlbaum Associates.

Fischer, R., Plessow, F., Dreisbach, G., \& Goschke, T. (2015). Individual differences in the context-dependent recruitment of cognitive control: Evidence from action versus state orientation. Journal of Personality, 83, 575-583.

Guevara, M. (1994). Alienation und Selbstkontrolle: Das Ignorieren eigener Gefühle. Frankfurt, Germany: Lang. 
Heinrichs, N., Rapee, R.M., Alden, L.A., Bögels, S., Hofmann, S.G., Oh, K.J., \& Sakano, Y. (2006). Cultural differences in perceived social norms and social anxiety. Behaviour Research \& Therapy, 44, 1187-1197.

Jostmann, N.B., \& Koole, S.L. (2006). On the waxing and waning of working memory: Action orientation moderates the impact of demanding relationship primes on working memory capacity. Personality and Social Psychology Bulletin, 32, $1716-1728$

Kaschel, R., Kazén, M., \& Kuhl, J. (2017). State orientation and memory load impair prospective memory performance in older compared to younger persons. Aging, Neuropsychology, and Cognition, 24, 453-469.

Kasser, T., \& Ahuvia, A. (2002). Materialistic values and wellbeing in business students. European Journal of Social Psychology, 32, 137-146.

Kasser, T., \& Sheldon, K. M. (2000). Of wealth and death: Materialism, mortality salience, and consumption behavior. Psychological Science, 11, 348-351.

Kazén, M., Baumann, N., \& Kuhl, J. (2003). Self-infiltration vs. self-compatibility checking in dealing with unattractive tasks: The moderating influence of state vs. action orientation. Motivation and Emotion, 27, 157-197.

Koole, S.L., \& Jostmann, N.B. (2004). Getting a grip on your feelings: effects of action orientation and external demands on intuitive affect regulation. Journal of Personality and Social Psychology, 87, 974-990.

Kuhl, J. (1984). Volitional aspects of achievement motivation and learned helplessness: Toward a comprehensive theory of action control. Progress in Experimental Personality Research, $13,99-171$.

Kuhl, J. (1985). Volitional mediators of cognition-behavior consistency: Self-regulatory processes and action versus state orientation. In J. Kuhl \& J. Beckmann (Eds.), Action control (pp. 101-128). Berlin: Springer.

Kuhl, J. (1987). Action control: The maintenance of motivational states. In N.F. Halisch \& J. Kuhl (Eds.), Motivation, intention, and volition (pp. 279-291). Berlin: Springer-Verlag.

Kuhl, J. (1994). Action versus state orientation: Psychometric properties of the Action Control Scale (ACS-90). In J. Kuhl \& J. Beckmann (Eds.), Volition and personality: Action versus state orientation (pp. 47-59). Göttingen, Germany: Hogrefe.

Kuhl, J. (2000). The volitional basis of personality systems interaction theory: Applications in learning and treatment contexts. International Journal of Educational Research, 33, 665703.

Kuhl, J. (2001). Motivation und Persönlichkeit: Interaktionen psychischer Systeme [Motivation and personality: Interactions of mental systems]. Göttingen, Germany: Hogrefe.

Kuhl, J., \& Beckmann, J. (Eds.). (1994). Volition and personality: Action versus state orientation: Göttingen, Germany: Hogrefe \& Huber.

Kuhl, J., \& Goschke, T. (1994). A theory of action control: Mental subsystems, modes of control, and volitional conflictresolution strategies. In J. Kuhl \& J. Beckmann (Eds.), Volition and personality: Action versus state orientation (pp. 93-124). Gottingen, Germany: Hogrefe.
Kuhl, J., \& Kazén, M. (1994). Self-discrimination and memory: State orientation and false self-ascription of assigned activities. Journal of Personality and Social Psychology, 66, 1103.

Kuhl, J., Quirin, M., \& Koole, S.L. (2015). Being someone: The integrated self as a neuropsychological system. Social and Personality Psychology Compass, 9, 115-132.

Landman, A., Nieuwenhuys, A., \& Oudejans, R.R. (2016). Decision-related action orientation predicts police officers' shooting performance under pressure. Anxiety, Stress, \& Coping, 29, 570-579.

Little, B.R. (1993). Personal projects and the distributed self: Aspects of a conative psychology. In J.M. Suis (Ed.), The self in social perspective: Psychological perspectives on the self (vol. 4, pp. 157-185). Hillsdale, NJ: Lawrence Erlbaum Associates.

Müller, F., \& Rothermund, K. (2017). Motive-goal congruence moderates the use of automatic self-regulation. Journal of Personality. Advance online publication. doi:10.1111/jopy.12355, 0.48

Ntoumanis, N., Healy, L.C., Sedikides, C., Duda, J., Stewart, B., Smith, A., \& Bond, J. (2014). When the going gets tough: The 'why' of goal striving matters. Journal of Personality, 82, 225-236.

Ruigendijk, H.A.H., \& Koole, S.L. (2014). When focusing on a goal interferes with action control: action versus state orientation and over-maintenance of intentions. Motivation \& Emotion, 38, 659-672.

Ryan, R.M. (1995). Psychological needs and the facilitation of integrative processes. Journal of Personality, 63, 397-427.

Ryan, R.M., Chirkov, V.I., Little, T.D., Sheldon, K.M., Timoshina, E., \& Deci, E.L. (1999). The American dream in Russia: Extrinsic aspirations and well-being in two cultures. Personality and Social Psychology Bulletin, 25, 1509-1524.

Ryan, R.M., \& Connell, J.P. (1989). Perceived locus of causality and internalization: Examining reasons for acting in two domains. Journal of Personality and Social Psychology, 57, 749-761.

Ryan, R.M., \& Deci, E.L. (2000). Self-determination theory and the facilitation of intrinsic motivation, social development, and well-being. American Psychologist, 55, 68-78.

Sheldon, K.M. (2008). The interface of motivational science and personology: Self-concordance, quality motivation, and multi-level personality integration. In J. Shah \& W. Gardner (Eds.), Handbook of motivational science (pp. 465-476). New York, NY: Guildford Press.

Sheldon, K.M. (2014). Becoming oneself: The central role of selfconcordant goal selection. Personality and Social Psychology Review, 18, 349-365.

Sheldon, K.M., \& Elliot, A.J. (1998). Not am personal goals are personal: Comparing autonomous and controlled reasons for goals as predictors of effort and attainment. Personality and Social Psychology, 24, 546-557.

Sheldon, K.M., \& Elliot, A.J. (1999). Goal striving, need satisfaction, and longitudinal well-being: The self-concordance model. Journal of Personality and Social Psychology, 76, 482-497. 
Sheldon, K.M., \& Kasser, T. (1998). Pursuing personal goals: Skills enable progress, but not all progress is beneficial. Personality and Social Psychology Bulletin, 24, 1319-1331.

Sheldon, K.M., \& Kasser, T. (2008). Psychological threat and extrinsic goal striving. Motivation and Emotion, 32, 37-45.

Sheldon, K.M., Ryan, R.M., Deci, E.L., \& Kasser, T. (2004). The independent effects of goal contents and motives on well-being: It's both what you pursue and why you pursue it. Personality and Social Psychology Bulletin, 30, 475-486.

Smith, A., Ntoumanis, N., \& Duda, J.L. (2007). Goal striving, goal attainment, and well-being: Adapting and testing the self-concordance model in sport. Journal of Sport \& Exercise Psychology, 29, 763-782.

Song, Z., Wanberg, C., Niu, X., \& Xie, Y. (2006). Action-state orientation and the theory of planned behavior: A study of job search in China. Journal of Vocational Behavior, 68, 490-503.
Thomsen, D.K., Tønnesvang, J., Schnieber, A., \& Olesen, M.H. (2011). Do people ruminate because they haven't digested their goals? The relations of rumination and reflection to goal internalization and ambivalence. Motivation and Emotion, $35,105-117$.

Triandis, H. (1988). Collectivism v. individualism: A reconceptualisation of a basic concept in cross-cultural social psychology. In C. Bagley \& G.K. Verma (Eds.), Personality, cognition and values: Cross-cultural perspectives of childhood and adolescence (pp. 60-95). London: Macmillan.

van Putten, M., Zeelenberg, M., \& van Dijk, E. (2013). How consumers deal with missed discounts: Transaction decoupling, action orientation and inaction inertia. Journal of Economic Psychology, 38, 104-110.

Wolff, M., Krönke, K.-M., Venz, J., Kräplin, A., Bühringer, G., Smolka, M.N., \& Goschke, T. (2016). Action versus state orientation moderates the impact of executive functioning on real-life self-control. Journal of Experimental Psychology: General, 145, 1635-1653. 